\title{
New developments in the management of partial-onset epilepsy: role of brivaracetam
}

\author{
This article was published in the following Dove Press journal: \\ Drug Design, Development and Therapy \\ 6 March 2017 \\ Number of times this article has been viewed
}

\author{
Giangennaro Coppola' \\ Giulia lapadre ${ }^{2}$ \\ Francesca Felicia Operto' \\ Alberto Verrotti ${ }^{2}$ \\ 'Unit of Child and Adolescent \\ Neuropsychiatry, Department of \\ Medicine and Surgery, University \\ of Salerno, Salerno, ${ }^{2}$ Department of \\ Pediatrics, University of L'Aquila, \\ L'Aquila, Italy
}

\begin{abstract}
Currently, a number of novel anticonvulsant drugs, the so-called third generation, are in various stages of development. Several of them are already available or in ongoing clinical trials. These new compounds should take advantage of new insights into the basic pathophysiology of epileptogenesis, drug metabolism and drug interactions. Many of them still need to be further evaluated mainly in real-world observational trials and registries. Among newer anticonvulsant drugs for partial-onset seizures (POSs), rufinamide, lacosamide, eslicarbazepine and perampanel are those new treatment options for which more substantial clinical evidence is currently available, both in adults and, to some extent, in children. Among the newest anticonvulsant drugs, brivaracetam, a high-affinity synaptic vesicle protein 2A ligand, reported to be 10 - to 30 -fold more potent than levetiracetam, is highly effective in a broad range of experimental models of focal and generalized seizures. Unlike levetiracetam, brivaracetam does not inhibit high-voltage $\mathrm{Ca}^{2+}$ channels and AMPA receptors and appears to inhibit neuronal voltage-gated sodium channels playing a role as a partial antagonist. Brivaracetam has a linear pharmacokinetic profile, is extensively metabolized and is excreted by urine (only $8 \%-11 \%$ unchanged). It does not seem to influence the pharmacokinetics of other antiepileptic drugs. It was approved in the European Union in January 2016 and in the US in February 2016 as an adjunctive therapy for the treatment of POS in patients older than 16 years of age. To date, its clinical efficacy as adjunctive antiepileptic treatment in adults with refractory POS at doses between 50 and $200 \mathrm{mg}$ daily has been extensively assessed in two Phase IIb and four Phase III randomized controlled studies. Long-term extension studies show sustained efficacy of brivaracetam. Overall, the drug is generally well tolerated with only mild-to-moderate side effects. This is true also by intravenous route. Brivaracetam has not yet been evaluated as monotherapy or in comparison with other new anticonvulsant drugs.
\end{abstract}

Keywords: brivaracetam, partial-onset seizures, epilepsy, antiepileptic drugs, adjunctive therapy

\section{Introduction to the classification of the partial-onset epileptic seizures}

In the proposal for the revision of seizures and epilepsies by Engel et al, ${ }^{1}$ the term "focal" was reintroduced instead of "partial". Furthermore, this new scheme abandons the division of focal seizures into "simple" and "complex" forms. The reason given is that this "inappropriately created the impression that impairment of consciousness had certain mechanistic implications related to limbic system involvement", and that "complex partial seizures" had been erroneously used as a synonym of "temporal lobe epilepsy".

More recently, in the International League Against Epilepsy (ILAE) 2010 report, Berg et $\mathrm{al}^{2}$ confirmed to remove the distinction between complex partial and simple partial, however, recognizing that impairment of consciousness/awareness or dyscognitive
Correspondence: Giangennaro Coppola Unit of Child and Adolescent

Neuropsychiatry, Department of Medicine and Surgery, S Giovanni di

Dio and Ruggi d'Aragona Hospital, University of Salerno, Largo d'lppocrate, Salerno 84100 , Italy

$\mathrm{Tel}+39089672578$

Email gcoppola@unisa.it
Drug Design, Development and Therapy 2017:I | 643-657

643

Dovepress f $y$ in $\mathbf{0}$

http://dx.doi.org/10.2147/DODTS103468 (c) (1) (\$) 2017 Coppola et al. This work is published and licensed by Dove Medical Press Limited. The full terms of this license are available at https://www.dovepress.com/terms.php

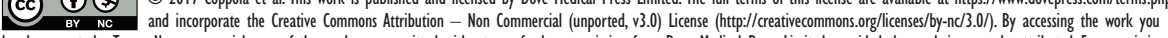
hereby accept the Terms. Non-commercial uses of the work are permitted without any further permisision from Dove Medical Press Limited, provided the work is properly attributed. For permission for commercial use of this work, please see paragraphs 4.2 and 5 of our Terms (https://www.dovepress.com/terms.php). 
features and localization and progression of ictal events can be of primary importance in the evaluation of individual patients and "for specific purposes" (ie, driving license and medicolegal purposes).

For pragmatic reasons and to facilitate continuity with the 1981 classification of seizures, descriptors of focal seizures may be used "individually or in combination with other features depending on the purpose". ${ }^{2}$

Following these criteria, "symptomatic temporal lobe epilepsy" should be turned into "temporal lobe epilepsy with seizure type (eg, dyscognitive and automotor) secondary to cortical dysplasia in the location (eg, left parahippocampal gyrus)".

\section{Epidemiology of focal-onset seizures}

Many epidemiological studies have reported the distribution of seizures and/or syndromes according to the ILAE classification.

The majority of studies have reported a slight predominance of focal seizures $(29.3 \%-63 \%)$ over generalized seizures $(12.9 \%-48 \%))^{3,4}$ The percentage distribution of focal seizures varies with age.

Within the group of focal seizures, symptomatic forms slightly prevail at all ages; indeed, genetic forms usually occur in children but tend to sharply decrease in favor of seizures related to unknown or structural/metabolic causes throughout adolescence and young adulthood.

In keeping with this, idiopathic epilepsy with centraltemporal spikes and Panayiotopoulos' benign focal epilepsy syndrome are among the most common childhood-onset epilepsy syndromes. The incidence of this syndrome is estimated to be 10/100,000 children per year. ${ }^{5}$

The incidence of focal-onset seizures is even higher in developing countries, on account of the significant presence of environmental risk factors such as perinatal cerebral insults, brain injuries and various parasitic diseases (malaria, onchocerciasis, cysticercosis or toxocariasis). ${ }^{6,7}$

\section{Current management strategies of focal seizures}

In this field, more criteria have to be considered including age (children, adolescents or adults), etiology (idiopathic or cryptosymptomatic), comedication, comorbidity, family planning, etc.

\section{Focal seizures in genetic epilepsies}

Benign seizures with central-temporal spikes (BECTS) and benign childhood occipital epilepsy fall within this group. In practice, the first question is whether medication is required. In fact, seizures can be single (10\% of BECTS) or occasional ( $\leq 3$ per year) and are age dependent.

However, when one decides to treat them, they are typically sensitive to a drug monotherapy. In the past, there were different approaches across countries (valproic acid [VPA] or carbamazepine [CBZ] in Europe, phenytoin [PHT] or CBZ in the US, clobazam in Canada, etc.), in the absence of controlled studies.

Although controlled studies have been carried out only for sulthiame and gabapentin, ${ }^{8,9}$ both of these drugs have not reached the level A or B according to the ILAE quality criteria for initial monotherapy in BECTS. ${ }^{10}$ Indeed, worsening of reading, memory and attention have been reported. ${ }^{11}$

Currently, oxcarbazepine (OXC) and levetiracetam (LEV) appear to be the most promising new drugs. ${ }^{12,13}$ Furthermore, HLA-B*15:02 screening methods should also be considered for the prevention of carbamazepine-induced severe drug reactions. ${ }^{14}$

\section{Focal seizures in cryptogenic/ symptomatic epilepsy}

With respect to focal seizures in adulthood, CBZ, levetiracetam (LEV), PHT, and zonisamide (ZNS) are recognized as level A antiepileptic drug (AED), while VPA as level B AED; CBZ, LTG, OXC, lamotrigine (LTG), phenobarbital $(\mathrm{PB})$, topiramate (TPM), and vigabatrin (VGB) are considered to be possibly efficacious/effective (level C), whereas clonazepam and primidone (PRM) are potentially efficacious/ effective (level D). ${ }^{15}$

In elderly adults, on the contrary, gabapentin (GBP) and LTG are well-established therapies (level A); CBZ is possibly (level C) and TPM and VPA are potentially (level D) efficacious/effective as initial monotherapy. The National Institute of Health and Clinical Excellence (NICE) guidelines (2012) recommend $\mathrm{CBZ}$ and LTG as first-choice drugs in children, adolescents and adults with cryptogenic focal seizures. In the event that these two AEDs are unsuitable or not tolerated, they suggest LEV, OXC or VPA, provided that the cost of LEV diminishes by at least 50\% compared to 2011 .

NICE (2012) also recommends adding a second AED when monotherapy with a second AED is ineffective.

In the event of refractory focal seizures, NICE suggests CBZ, clobazam, GBP, LTG, LEV, OXC, VPA or TPM as additional medications if first-line treatments are ineffective or not tolerated. We should also pay special attention to the teratogenic or neurodevelopmental adverse effects of VPA.

Carbamazepine is the therapy of choice for children in most countries, whereas VPA is preferred for small children until the focal component of the epilepsy has been identified. ${ }^{17}$ 
Although CBZ, VPA, PHT and PB were found to be equally effective in newly diagnosed children, ${ }^{16}$ evident concerns undoubtedly exist regarding cognitive--behavioral effects, especially related to $\mathrm{PB}$ and $\mathrm{PHT} .{ }^{10} \mathrm{OXC}$ remains a possible alternative as initial monotherapy for children aged 4 years and older in view of its effectiveness, good tolerability and absence of drug interactions. ${ }^{18}$

Before starting treatment with $\mathrm{CBZ}$ or $\mathrm{OXC}$, the opportunity to perform a HLA genetic profile to assess the potential risk of vasculitic reactions should be taken into consideration. ${ }^{14}$

Clobazam is considered a first-choice drug in some countries. ${ }^{19,20}$

For refractory cases, a second-line strategy includes five AEDs (LTG, TPM, GBP, OXC, LEV) for which there are placebo (PBO)-controlled randomized studies. The responder rates substantially overlap (range $21 \%-45 \%$ ) with an average of $19 \%$ in the PBO groups.

The preference for a given drug is also based on the experience of the physician, on potential drug-drug interactions, on the need for rapid titration (LEV, GBP) in the presence of frequent seizures.

In infants, effective drugs are OXC $(60 \mathrm{mg} / \mathrm{kg}$ is more effective than $10 \mathrm{mg} / \mathrm{kg}$ ), lamotrigine and LEV compared to $\mathrm{PBO} .^{21,22}$

\section{Emerging treatment options for partial-onset seizures (POSs)}

The need for new AEDs, the so-called third generation, is based on the persistence, in a considerable number of patients of any age, of problems related to the second-generation drugs, which include the following: persistent drug resistance, dose-dependent idiosyncratic adverse effects and drug interactions.

Currently, a number of novel AEDs are in various stages of development. Several of them are already available or in ongoing clinical trials. These new compounds should take advantage of new insights into the basic pathophysiology of epileptogenesis, drug metabolism and drug interactions. Many of them still need to be further evaluated, mainly in real-world clinical observational trials and registries.

Among newer AEDs for POSs, rufinamide, lacosamide (LCM), eslicarbazepine (ESL), perampanel (PER) and brivaracetam (BRV) are briefly considered in the following sections in view of the fact that there is more substantial evidence on them both in adults and, to some extent, in children.

\section{Rufinamide}

Rufinamide is a compound not related to the existing AEDs, which inactivates the voltage-gated sodium channels
(VGSCs). Rufinamide has been designated in Europe and the US by the Food and Drug Administration (FDA) as orphan drug for adjunctive treatment for Lennox-Gastaut syndrome with drop attacks. Perhaps, this recognition has hampered its broader assessment for focal seizures in both children and adults. However, there is increasing evidence for the effectiveness of Rufinamide (RUF) even in partial seizures, initially in adults with $28.2 \%$ responder rate ${ }^{23}$ and in children and adolescents with drug-resistant partial seizures. ${ }^{24-26}$ In these studies, the responder rate ranged between 42 and $46 \%$ of treated patients. Some of the data seem to suggest good efficacy against seizures originating in the frontal lobe ${ }^{27}$ and those secondary to neuronal migration disorders. ${ }^{28}$

\section{Eslicarbazepine}

ESL is a third-generation AED structurally related to $\mathrm{CBZ}$ and OXC, approved by European Medicines Agency (EMA) in 2009 and by FDA in 2013 as an adjunctive drug in the treatment of focal-onset seizures with or without secondary generalization in adults. ESL works by blocking the VGSCs. A responder rate between 17 and $43 \%$ was seen in four Phase III randomized controlled studies in subjects aged $\geq 18$ or 16 years with refractory POSs. ${ }^{29,30}$

ESL was significantly more effective than PBO at the dose of 1,200 mg once daily. The efficacy of adjunctive ESL acetate was maintained in the longer term (up to 2 years) according to the results of extension studies. ${ }^{31-33}$ Overall, these medications were well tolerated and safe, most adverse events (AEs) being of mild-to-moderate severity. More recently, ESL acetate was licensed as monotherapy for POS in adults in the US and Europe based on two randomized, double-blind, conversion-to-monotherapy Phase III trials $(1,200$ or $1,600 \mathrm{mg}$ once daily) in patients with uncontrolled partial epilepsy. ${ }^{34}$

In addition, an overnight switch from twice-daily $\mathrm{OXC}$ to once-daily ESL in patients with partial-onset epilepsy resulted in improvement in side effects, alertness and quality of life. ${ }^{35}$

Although ESL is currently not allowed under 18 years of age, a favorable pharmacokinetic, tolerability and efficacy profile has been reported in preliminary studies in children, ${ }^{36,37}$ thus suggesting that the drug may be useful in the management of epileptic children.

\section{Lacosamide}

LCM, a third-generation AED, is a functionalized amino acid first approved in 2008 as add-on drug for refractory POS in adults older than 17 years and then approved in 2014 as monotherapy for POS by FDA (US). Unlike traditional 
sodium channel blockers affecting fast inactivation, LCM selectively enhances sodium channel slow inactivation. As adjunctive drug for focal-onset seizures, LCM in three randomized controlled, dose-ranging trials (200-600 mg/day) including 1,311 participants, led to a significant seizure reduction as well as seizure freedom compared to $\mathrm{PBO}$ over a period ranging from 24 to 26 weeks. Overall, LCM was well tolerated, although higher doses of LCM were associated with a higher incidence of AEs. More recently, LCM resulted to be efficacious as adjunctive treatment or conversion monotherapy, in temporal lobe epilepsy regardless of the presence of hippocampal sclerosis, at the daily dose of $200-400 \mathrm{mg}$ in adult patients. ${ }^{38}$

Furthermore, LCM may work better as first add-on than later adjunctive treatment for uncontrolled POS. ${ }^{39,40}$ Several recent experiences suggest that LCM monotherapy, either as first-line or after conversion, may be a valuable option, even in the long term, for patients with focal epilepsy. ${ }^{41-43}$ The most common treatment-emergent adverse effects (TEAEs) with this drug are dizziness, headache and somnolence; ${ }^{39}$ nonetheless, planned reduction in concomitant AEDs during LCM initiation and the use of non-sodium channel blockers agents only are associated with a reduced risk of TEAEs. ${ }^{44}$ Currently, the lack of head-to-head comparisons with other AEDs prevents an exact positioning of LCM in the therapeutic schedule of focal seizures.

\section{Perampanel}

PER is an AMPA receptor antagonist first licensed for the treatment of focal seizures with or without secondary generalization in adults and children 12 years of age and over, following the completion of a number of dose-ranging, PBOcontrolled trials, in which it was used as adjunctive therapy. ${ }^{45}$ These studies compared 4, 8 and $12 \mathrm{mg}$ daily doses of PER at bedtime with PBO. More recently, PER has been approved as add-on medication for primary generalized tonic-clonic seizures epilepsy.

In most clinical studies, the responder rate was $25 \%-38 \%$ and the most effective daily doses were $8-12 \mathrm{mg}$. However, a number of patients may significantly improve also with $4 \mathrm{mg} /$ day.

Seizure freedom was reported in $2.6 \%-6.4 \%$ of patients with 8-12 mg of PER daily.

Overall, PER was safe, well tolerated and effective. The most frequent dose-correlated TEAEs were sleepiness, behavioral problems and dizziness. In addition, PER does not alter cognition significantly. ${ }^{46}$

\section{Epilepsy treatment options other than drugs}

Although many children and adults with epilepsy respond more or less quickly to drug medications, $\sim 25 \%-30 \%$ of them develop drug resistance, often combined with worrisome systemic and/or cognitive-behavioral adverse side effects.

The next step is then to consider surgical approach that is especially suitable for well-localized epileptogenic brain lesions. However, when they are present in eloquent areas (eg, motor, language or memory) or in the event of multifocal epilepsies, surgery is not easily applicable. For this reason, only $\sim 5 \%$ of patients are candidates for epilepsy surgery, to date.

Temporal and extratemporal lobe surgeries most frequently include hippocampal sclerosis and/or focal cortical dysplasias, clastic lesions and cortical malformations, brain tumors, vascular lesions and hypothalamic hamartomas, albeit with differences concerning clinical approach and neuropsychological outcome between adults and children. Surgical resolution of epilepsy can reach up to $80 \%-90 \%$ of patients, and it is now recommended as early as possible in specific conditions.

When surgical treatment is not applicable for different reasons, epileptologists should consider non-pharmacological approaches including diet and neurostimulation.

The former includes different ketogenic and less ketogenic regimens such as the classic 4:1 ketogenic diet, the modified Atkins diet (MAD), the low glycemic index treatment (LGIT) and the medium-chain triglyceride (MCT) diet, which are feasible not only in childhood but also in adults. ${ }^{47}$ If diets are ineffective, neurostimulation is often the next viable option. Beyond the well-known vagus nerve stimulation (VNS), ${ }^{48}$ electrical stimulation to suppress seizure activity can be provided directly to the brain by means of deep brain stimulation (DBS; eg, thalamic nuclei) or the brain cortex, using a cortical device which is "responsive" as it detects seizure activity and subsequently disrupts it via electrical stimulation to the cortex (responsive neurostimulator, NRS) ${ }^{49}$ Finally, transcranial magnetic stimulation (TMS) is a method of stimulation using magnetic fields rather than electricity to reduce seizure frequency. ${ }^{50}$

\section{Brivaracetam}

The pharmacokinetic/dynamic features, as well as the clinical efficacy and tolerability of BRV, are presented and discussed in the following sections. 


\section{Mode of action}

BRV is a selective, high-affinity and reversible SV2A ligand. SV2A is a glycoprotein located in the presynaptic membrane and ubiquitously expressed in the brain, which is involved in the modulation of synaptic vesicle exocytosis and neurotransmitter release. ${ }^{51}$ In particular, SV2A seems to have an important role in epileptogenesis, as reported for transgenic mice in which SV2A deficiency led to increased seizure vulnerability. ${ }^{52}$ The exact mechanism whereby ligand binding to SV2A reduces seizure susceptibility is still unclear. Nevertheless, several attempts have been made in this way.

Rationally designed to have a higher affinity and selectivity for SV2A with respect to its analog LEV, BRV shows a 15- to 30-fold higher binding affinity to SV2A than LEV, demonstrated in both animal and human brains. ${ }^{53,54}$

BRV also shows high binding selectivity. In fact, in vitro experiments reported that at the concentration of $10 \mu \mathrm{M}$ (more than a 100-fold above its affinity for SV2A), it did not bind, activate or inhibit a panel of 55 other receptors, channels and enzymes potentially involved in epilepsy. ${ }^{54}$ In addition, results from SV2A knockout mice showed that up to the concentration of $600 \mathrm{nM}$ (the highest concentration tested), $\left[{ }^{3} \mathrm{H}\right] \mathrm{BRV}$ only labeled SV2A proteins. A recent study has revealed that BRV, similar to LEV, enters into recycling synaptic vesicles, producing a frequency-dependent decrease in synaptic transmission at 100-fold lower concentrations than LEV. Moreover, BRV was more effective than LEV in slowing synaptic vesicle mobilization. ${ }^{55}$

In addition, BRV displays inhibitory activity on VGSCs, ${ }^{56}$ which, however, seems not to represent a relevant mechanism involved in its anticonvulsant properties. In fact, a study assessing BRV pharmacology on VGSCs in different cell systems, and evaluating the efficacy of BRV in reducing sustained repetitive firing (SRF) in comparison to carbamazepine, revealed a substantial lack of effect of BRV on SRF in neurons, suggesting that none of its antiepileptic effects are mediated by VGSC blockade. ${ }^{57}$

\section{Pharmacokinetics of BRV}

The pharmacokinetic properties of BRV have been studied extensively. Clinical trials have been conducted in adult healthy volunteers, in the elderly, in patients with epilepsy and in those with hepatic or renal impairment, revealing only minor differences not requiring any dose adjustment. In particular, in healthy adults, BRV exhibited a linear pharmacokinetic profile over a broad range of doses (single doses: 10-1,400 mg; multiple doses: $200-800 \mathrm{mg}$ daily) with low interindividual variability. ${ }^{58,59}$ After oral administration, BRV was quickly and almost completely absorbed throughout the gastrointestinal $\operatorname{tract}^{60}$ with a median $T_{\text {max }}$ of $\sim 1-2 \mathrm{~h} .{ }^{58,59} C_{\text {max }}$ showed a dose-proportional trend from 10 to $1,400 \mathrm{mg}$, while area under the curve (AUC) profile maintained dose linearity until $600 \mathrm{mg} .{ }^{58}$ Absorption of BRV was not affected by food ingestion: a high-fat meal had the effect of delaying $T_{\max }(3 \mathrm{~h})$ and decreasing $C_{\max }$, but caused no modification of AUC. ${ }^{58}$ Its distribution volume $(0.6 \mathrm{~L} / \mathrm{kg})$ was slightly lower than total body water, and a small proportion $(<20 \%)$ was weakly bound to plasma proteins. ${ }^{58,61}$ Thanks to its ability to cross mucous membranes, BRV saliva and plasma levels were closely correlated, suggesting that saliva could be a suitable sample for monitoring BRV plasma concentrations when blood samples are unavailable. ${ }^{59}$

BRV has a fast onset of action; pharmacologic peak activity and peak plasma levels occur simultaneously, after a single oral dose of the drug. In contrast, LEV maximum plasma activity follows maximum plasma concentrations by almost $1 \mathrm{~h}$. This remarkable property derives from its lipophilicity, which enables BRV to optimally penetrate into the brain. ${ }^{62}$ In fact, as reported for rodents, BRV shows a faster entry into the brain than LEV and a faster onset of action against seizure in audiogenic mice, suggesting that BRV may offer benefits in the treatment of acute seizures.

A small fraction of the dose $(5 \%-8 \%)$ is excreted unchanged in the urine with a large amount of inactive metabolites (acid, hydroxy and hydroxy acid derivatives). BRV is extensively metabolized throughout two main metabolic pathways, including hepatic hydrolysis of the acetamide group and hydroxylation by cytochrome (CYP) P450 2C19. Renal clearance of the parent drug is low $(0.04$ per $\mathrm{min} / \mathrm{kg})$ and $>95 \%$ of the dose is eliminated by renal excretion within $72 \mathrm{~h}$. BRV plasma half-life is $\sim 7-8 \mathrm{~h}^{58,61}$

Patients with inactive mutations of CYP2C19 show only minor reduction (29\%) in BRV clearance, which is probably not clinically significant. Thus, individuals with CYP2C19 genetic polymorphisms do not require any dose adjustment. ${ }^{63}$

In patients with severe renal impairment, defined as creatinine clearance $>30 \mathrm{~mL} / \mathrm{min}$, major exposure $(>20 \%)$ to BRV has been reported, in addition to increased levels of its metabolites. Nevertheless, dose reduction is not required due to the inactivity and low toxicity of BRV metabolites. ${ }^{64}$

In individuals with hepatic impairment, $25 \%-35 \%$ reduction in BRV clearance and, therefore, increase in exposure to 
BRV with a prolonged half-life to $14-17 \mathrm{~h}$ are reported, with a consequent need for reduction by one-third of the maximum daily dose of the drug in this group of patients. ${ }^{65}$

\section{Comparative efficacy, safety and tolerability of BRV}

\section{Efficacy}

BRV as adjunctive therapy: Clinical efficacy of BRV as adjunctive antiepileptic treatment has been extensively assessed in six randomized controlled trials (RCTs): two Phase IIb $^{66,67}$ and four Phase III studies, ${ }^{68-70}$ including a total of 2,393 adult patients (aged 16-80 years) affected by refractory POS, and the results are reported in Table 1.

\section{Phase llb studies}

In the first trial, ${ }^{66} 210$ patients aged $16-65$ years, with refractory POS, were randomized to PBO, BRV 5, 20 or $50 \mathrm{mg} /$ day b.i.d., without up-titration, for a treatment period of 7 weeks. Statistically significant percentage reductions over PBO in POS frequency/week were reported for the $50 \mathrm{mg} /$ day group $(22.1 \%, P=0.004)$, but not for the 5 or $20 \mathrm{mg} /$ day group. Similarly, the percentage reduction from baseline in weekly POS frequency during the treatment period was significant in the $50 \mathrm{mg} /$ day group $(28.7 \%, P<0.001)$ and in the $20 \mathrm{mg} /$ day group $(22.5 \%, P=0.0014)$, but not in the $5 \mathrm{mg} /$ day group. Fifty percent responder rates from baseline in terms of weekly POS frequency were significant for all three BRV groups (5 mg/day 32.0\%, $P=0.047 ; 20 \mathrm{mg} /$ day $44.2 \%, P=0.0002 ; 50 \mathrm{mg} /$ day $55.8 \%, P<0.0001)$. Percentages of seizure freedom achieved by participants during the 7-week treatment period were not statistically significant for any of the BRV groups: $1.9 \%$ for PBO, $8.0 \%$ for BRV 5, 7.7\% for BRV 20 and 7.7\% for BRV 50. BRV proved to be effective as adjunctive treatment in adults with POS, showing a dose-related efficacy profile for doses ranging from 5 to $50 \mathrm{mg} /$ day.

The second study ${ }^{67}$ included 157 adult patients with similar characteristics at enrollment, who were randomized to receive PBO, BRV 50 or $150 \mathrm{mg}$ /day b.i.d., for a 3-week up-titration period, followed by a 7-week maintenance period. Reduction rate in seizure frequency/week over PBO during the entire treatment period was not statistically significant for any group. Percentage reduction from baseline in weekly POS frequency during the maintenance period was significant for $50 \mathrm{mg} /$ day $(38.2 \%, P=0.017)$, but not for $150 \mathrm{mg}$ /day versus PBO. Fifty percent responder rates from baseline during the whole treatment period were significant for $50 \mathrm{mg} /$ day $(35.8 \%, P=0.038)$, but not for $150 \mathrm{mg} /$ day.

Table I Efficacy end points from Phase II and Phase III RCTs

\begin{tabular}{|c|c|c|c|c|c|c|c|c|}
\hline Study & $\begin{array}{l}\text { ITT } \\
\text { population }\end{array}$ & $\begin{array}{l}\text { Up-titration } \\
\text { period }\end{array}$ & $\begin{array}{l}\text { Treatment } \\
\text { dose (mg/day) } \\
\text { and number of } \\
\text { patients }(n)\end{array}$ & $\begin{array}{l}\geq 50 \% \\
\text { responder } \\
\text { rate }\end{array}$ & $\begin{array}{l}\text { Seizure } \\
\text { freedom } \\
(\%)\end{array}$ & $\begin{array}{l}\text { Seizure } \\
\text { reductions } \\
\text { over } \\
\text { PBO/week } \\
(\%)\end{array}$ & $\begin{array}{l}\text { Seizure } \\
\text { reductions } \\
\text { over } \\
\text { PBO/28 days } \\
\text { (\%) }\end{array}$ & $\begin{array}{l}\text { Median\% } \\
\text { reduction } \\
\text { from baseline } \\
\text { in seizure } \\
\text { frequency/week }\end{array}$ \\
\hline French & 208 & No & PBO $(n=54)$ & 16.7 & 1.9 (NS) & - & - & 21.7 \\
\hline \multirow[t]{3}{*}{ et $\mathrm{al}^{66}$} & & & BRV $5(n=50)$ & $32.0, P=0.047$ & 8.0 (NS) & 9.8 (NS) & - & 29.9 (NS) \\
\hline & & & BRV $20(n=52)$ & $44.2, P=0.0002$ & 7.7 (NS) & 14.9 (NS) & - & $42.6, P=0.0014$ \\
\hline & & & BRV $50(n=52)$ & $55.8, P<0.0001$ & 7.7 (NS) & 22. $I, P=0.004$ & - & 53. I, $P<0.001$ \\
\hline Van & 157 & Yes & PBO $(n=52)$ & 23.1 & 1.9 & - & - & 18.9 \\
\hline Paesschen & & & BRV $50(n=53)$ & 39.6 (NS) & 9.4 & $17.7, P=0.026$ & - & $38.2, P=0.017$ \\
\hline et $\mathrm{al}^{67}$ & & & BRV I $50(n=52)$ & 33.3 (NS) & 5.8 & $16.3, P=0.043$ & - & 30.0 (NS) \\
\hline Kwan & 480 & No & $\operatorname{PBO}(n=|2|)$ & 16.7 & 0 & - & - & 18.9 \\
\hline et $\mathrm{al}^{68}$ & & & BRV $20-150(n=359)$ & $30.3, P=0.006$ & $\mathrm{I} .5$ (NS) & 7.3 (NS) & - & 26.9 (NS) \\
\hline \multirow[t]{4}{*}{ Biton et $\mathrm{al}^{69}$} & 396 & No & $\mathrm{PBO}(\mathrm{n}=98)$ & 16.7 (NS) & 0 & - & - & 17.8 \\
\hline & & & BRV $5(n=97)$ & 21.9 (NS) & I.I (NS) & 0.9 (NS) & 2.6 (NS) & 20.0 (NS) \\
\hline & & & BRV $20(n=100)$ & 23.2 (NS) & I.0 (NS) & 4.1 (NS) & 8.7 (NS) & 22.5 (NS) \\
\hline & & & BRV $50(n=101)$ & $32.7, P=0.008$ & 4 & $12.8, P=0.025$ & $22.0, P=0.004$ & $30.5, P=0.003$ \\
\hline Ryvlin & 398 & No & PBO $(n=100)$ & 20.0 (NS) & 0 & - & - & 17 \\
\hline \multirow[t]{3}{*}{ et $\mathrm{al}^{70}$} & & & BRV $20(n=99)$ & 27.3 (NS) & 2 & 6.8 (NS) & 10.2 (NS) & $30.0, P=0.019$ \\
\hline & & & BRV $50(n=99)$ & 27.3 (NS) & 0 & 6.5 (NS) & 9.2 (NS) & 26.8 (NS) \\
\hline & & & BRV $100(n=100)$ & $36.0, P=0.023$ & 4 & II.7, P=0.037 & $20.5, P=0.010$ & $32.5, P=0.004$ \\
\hline \multirow[t]{3}{*}{ Klein et $\mathrm{al}^{71}$} & 760 & No & PBO $(n=259)$ & 21.6 & 0.8 & - & - & 17.6 \\
\hline & & & BRV $100(n=252)$ & $38.9, P<0.001$ & $5.2, P=0.003$ & - & $22.8, P<0.001$ & $37.2, P<0.001$ \\
\hline & & & BRV $200(n=249)$ & $37.8, P<0.001$ & $4.0, P=0.019$ & - & $23.2, P<0.001$ & $35.6, P<0.001$ \\
\hline
\end{tabular}

Abbreviations: BRV, brivaracetam; ITT, intent-to-treat; NS, not significant; PBO, placebo; RCTs, randomized controlled trials. 


\section{Phase III studies}

Four randomized, double-blind, PBO-controlled Phase III trials $^{68-71}$ including a total of $>2,000$ adult patients have been conducted to evaluate BRV as add-on treatment in refractory POS. In particular, one flexible dose and three fixed-dose studies are available. ${ }^{68-71}$

The flexible-dose trial ${ }^{68}$ was designed to assess safety and tolerability of BRV as primary outcome, efficacy being a secondary objective. The study included 480 adult patients, aged 16-70 years, affected by untreatable epilepsy (431 had focal epilepsy and 49 had primary generalized epilepsy). After a prospective 4-week baseline, patients were randomized to b.i.d. BRV or PBO. BRV was introduced at the daily dose of $20 \mathrm{mg}$ and increased up to $50,100 \mathrm{or} 150 \mathrm{mg}$, at intervals of 2 weeks, based on the investigator's assessment of efficacy and tolerability. The dose-finding period lasted for 8 weeks, followed by an 8 -week dose maintenance period, for the whole treatment period of 16 weeks. Twenty percent of patients received concomitant LEV. The final dose of $100-150 \mathrm{mg}$ /day was given to $71.6 \%$ of BRV-treated patients, while $20-50 \mathrm{mg} /$ day dose was administered to the other patients. Ninety percent of BRV-treated patients and $91.7 \%$ of PBO-receiving patients were able to complete the study. In patients with focal epilepsy, both the baselineadjusted percent reduction in BRV over PBO group and the median percent reduction in seizure frequency/week during the treatment period were not statistically significant. On the other hand, $\geq 50 \%$ responder rate was significant for BRV (30.3\% BRV versus $16.7 \% \mathrm{PBO}, P=0.006)$. In patients with primary generalized epilepsy, the median reduction rate from baseline in weekly seizure frequency was $42.6 \%$ versus $20.7 \%$, and the $\geq 50 \%$ responder rate was $44.4 \%$ versus $15.4 \%$ in $B R V$-treated and PBO-treated patients, respectively. In terms of baseline-adjusted percent reduction in focal seizure frequency/week during the treatment period, better results were reported for patients in the BRV group, not receiving concomitant LEV, than for patients using LEV concomitantly. Differences in achieving seizure freedom were not significant between the two groups (1.5\% BRV group, compared with $0 \%$ PBO group).

The three fixed-dose studies were all similarly designed. The first of these, ${ }^{69}$ included 400 adult patients aged 16-70 years, affected by drug-resistant POS. They were recruited in Australia, Brazil, Canada, Mexico and the US. Concomitant LEV was used by $20 \%$ of patients. After an 8-week prospective baseline period, patients were randomized to receive $\mathrm{PBO}$ or $\mathrm{BRV}(5,20$ or $50 \mathrm{mg}$ /day) during a 12 -week treatment period. Approximately $91.2 \%$ of patients completed the study. Percent reduction in POS frequency/ week over PBO was significant for BRV $50 \mathrm{mg} /$ day (12.8\%; $P=0.025$ ), but not for BRV $20 \mathrm{mg} /$ day (4.1\%) or for BRV $5 \mathrm{mg} /$ day $(0.9 \%)$. The percent reduction over PBO was statistically significant in terms of baseline-adjusted seizure frequency/28 days for BRV $50 \mathrm{mg} /$ day $(22.0 \% ; P=0.004)$ but not for the other BRV groups. In the BRV $50 \mathrm{mg} /$ day group, statistical significance was also reported for the $\geq 50 \%$ responder rate (BRV $32.7 \%$ versus PBO 16.7\%; $P=0.008$ ) and median percent reduction from baseline in seizure frequency/week (BRV 30.5\% versus PBO 17.8\%; $P=0.003$ ). Good results, in terms of efficacy, were reported for both patients who had already used LEV (BRV 20 and $50 \mathrm{mg}$ /day groups) and patients who were LEV naive (all doses), while the efficacy in patients using concomitant LEV was lower, suggesting a limited effect of BRV when it is used combined with LEV.

The second study ${ }^{70}$ included 399 adults from Europe and India, with refractory POS, aged 16-70 years. After an 8-week prospective baseline, patients were randomized to receive $\mathrm{PBO}$ or 20,50 and $100 \mathrm{mg} /$ day BRV during a 12-week period. Concomitant use of LEV was reported in $20 \%$ of randomized patients. Percent reduction over PBO in baseline-adjusted seizure frequency/week was not statistically significant for BRV 20 and $50 \mathrm{mg}$ /day dose (6.8 and $6.5 \%$, respectively), while it was statistically significant for BRV $100 \mathrm{mg} /$ day $(11.7 \% ; P=0.037)$. On the contrary, a significant median percent reduction from baseline in seizure frequency/week was seen for BRV $20(30.0 \% ; P=0.019)$ and for BRV 100 (32.5\%; $P=0.004)$, but not for BRV $50 \mathrm{mg} /$ day, compared with $\mathrm{PBO}$. In terms of $\geq 50 \%$ responder rates, a statistical significance was observed only in the BRV $100 \mathrm{mg} /$ day group $(36.0 \% ; P=0.023)$.

The third study ${ }^{71}$ was conducted in a very large population of 768 adults with uncontrolled POS despite treatment with 1-2 antiepileptic drugs. After an 8-week prospective baseline period, patients were randomized to $\mathrm{PBO}, \mathrm{BRV} 100 \mathrm{mg} /$ day or BRV $200 \mathrm{mg} /$ day. Treatment period lasted for 12 weeks. Percent reduction over PBO in 28-day adjusted seizure frequency was statistically significant for both BRV $100 \mathrm{mg} /$ day (22.8\%; $P<0.001)$ and BRV $200 \mathrm{mg} /$ day $(23.2 \% ; P<0.001)$. Similarly, also the $\geq 50 \%$ responder rates were statistically significant for both the BRV groups $(38.9 \% ; P<0.001$ for BRV $100 \mathrm{mg} /$ day and $37.8 \%$ for BRV $200 \mathrm{mg} /$ day, respectively) compared with $21.6 \%$ for PBO. Add-on BRV was effective in reducing POS in adults who did not use concomitant LEV and led to significantly higher seizurefree rates (5.2 and 4.0\%, respectively) than PBO $(0.8 \%)$. 
Interestingly, no dose-dependent effect was found between the dosage regimen of 100 and $200 \mathrm{mg} /$ day.

To summarize, the primary efficacy end point in all Phase II and Phase III fixed-dose studies was the reduction rate in seizure frequency over PBO. Concerning to this, BRV was found to be efficacious at $50 \mathrm{mg}$ /day dose, but not at 20 or $5 \mathrm{mg} /$ day dose. ${ }^{66,69}$ Two studies failed to show efficacy for BRV $50 \mathrm{mg} /$ day dose. ${ }^{67,70}$ Moreover, statistically significant PBO-adjusted seizure reduction was found for BRV $100 \mathrm{mg} /$ day dose in two Phase III trials, ${ }^{70,71}$ and for BRV daily dose of $200 \mathrm{mg} .^{71} \mathrm{BRV} 150 \mathrm{mg}$ did not meet the primary efficacy outcome when administered in the second Phase II study. ${ }^{67}$ Median percent baseline-adjusted seizure reduction and $\geq 50 \%$ responder rates, considered as secondary endpoints, were achieved at the dose of BRV 5, 20 and $50 \mathrm{mg} /$ day in the first Phase II study ${ }^{70}$ and at the dose of $50 \mathrm{mg},{ }^{67,69}$ but not $150 \mathrm{mg} /$ day in the second Phase II study. ${ }^{67}$ Good results were reported also for the daily dose of $100^{70,71}$ and $200 \mathrm{mg}^{.71}$

\section{Meta-analyses}

To date, three meta-analyses ${ }^{72-74}$ have systematically assessed the efficacy and safety of BRV compared with PBO as adjunctive therapy for adults with refractory POS. In the first two articles, ${ }^{72,73}$ five RCTs were reviewed, including a total of 1,639 patients; $50 \%$ responder rates and seizure-free rates were analyzed as end points for evaluating BRV efficacy. Fifty percent responder rates among patients treated with BRV 20, 50 or $100 \mathrm{mg}$ /day were significantly higher than among patients receiving PBO (20 mg: relative risk $[\mathrm{RR}]=1.63,95 \% \mathrm{CI}=1.18-2.27, P=0.003 ; 50 \mathrm{mg}: \mathrm{RR}=2.00$, 95\% CI $=1.50-2.66, P<0.00001 ; 100 \mathrm{mg}: \mathrm{RR}=1.80,95 \%$ $\mathrm{CI}=1.12-2.88, P=0.01$ ), while no statistically significant difference emerged from the comparison between PBO and the BRV daily dosage of 5 or $150 \mathrm{mg}$. In terms of seizure freedom, BRV was found to be significantly effective, in all BRV groups regardless of dosage, compared to PBO.$^{72}$ In the most recent meta-analysis ${ }^{74}$ including six RCTs for a total of 2,399 patients, BRV efficacy was evaluated in terms of $\geq 50 \%$ responder rates and seizure-free rates. Compared to $\mathrm{PBO}, \mathrm{BRV}$ was more efficacious in decreasing seizure frequency by $50 \%$ or more at BRV daily dose ranging from 20 to $200 \mathrm{mg}$, suggesting a dose-related effect up to the dosage of $50 \mathrm{mg}$ daily. In addition, the subanalysis by LEV status showed greater efficacy of BRV in LEV-naive patients, although larger studies are required to confirm this finding. ${ }^{74}$

In conclusion, overall data demonstrated that BRV is effective, at the dosage of $20-200 \mathrm{mg} /$ day, in reducing seizure frequency in adult patients with refractory partialonset epilepsy.

\section{Long-term extension studies}

Patients who completed the two Phase II studies, ${ }^{66,67}$ the four (three fixed ${ }^{69-71}$ and one flexible dose ${ }^{68}$ ) Phase III studies and the Phase III intravenous (IV) study ${ }^{75}$ were offered to enter one of three long-term follow-up (LTFU) studies, to assess safety, tolerability and seizure control during long-term treatment with adjunctive BRV. Out of 2,186 BRV-treated patients, 93.8\% (2,051) completed core studies and entered LFTU. Some of them continued to receive BRV for $>8$ years. Enrolled patients received a flexible dose of BRV add-on treatment, starting from the same daily dosage they received at the end of the previous study or $150 \mathrm{mg}$, up to a maximum of $200 \mathrm{mg}$. Data were analyzed until January 2014. At the clinical cutoff date, BRV exposure was up to 96 months for one LTFU trial. As reported in a pooled analysis, ${ }^{76}$ the overall median baseline-adjusted reduction in POS/28 days was $48.8 \%$, which increased from $43.1 \%$ for the 1,834 patients who received BRV during a 1-3-month period, to $77 \%$ for the 540 patients receiving BRV for 58-60 months. Similarly, the percentage of patients with a $\geq 50 \%$ response increased over time, from $43.5 \%$ for $1-3$ months to $71.0 \%$ for 58-60 months. Seizure-free rates for the first 6, 12, 24 and 60 months of BRV exposure were 4.9, 4.2, 3.0 and 3.3\%, respectively. In conclusion, these LTFU studies strongly support the efficacy of BRV antiepileptic activity, also for prolonged periods.

\section{Safety and tolerability}

\section{$B R V$ as adjunctive therapy}

Safety and tolerability of oral administration of BRV as adjunctive treatment in adults with uncontrolled focal epilepsy have been carefully evaluated in six RCTs, ${ }^{66-71}$ and the results are given in Table 2 .

At the recommended dosage range of 50-200 mg/day, BRV was generally well tolerated in adult patients (aged $\geq 16$ years). Most AEs were mild to moderate and related to the central nervous system.

As reported in a recent meta-analysis, ${ }^{74}$ including all six RCTs, ${ }^{66-71}$ BRV showed an overall safety profile, as confirmed by treatment withdrawal rates, which was similar to $\mathrm{PBO}$ across all BRV doses. The most frequent TEAEs and their incidence rates among patients receiving BRV were $12.4 \%$ for somnolence, $10.4 \%$ for headache, $9.6 \%$ for dizziness, $7.7 \%$ for fatigue, $4.9 \%$ for nausea, $4.2 \%$ for nasopharyngitis, $2.8 \%$ for irritability, $2.5 \%$ for insomnia, $2.0 \%$ for anxiety 


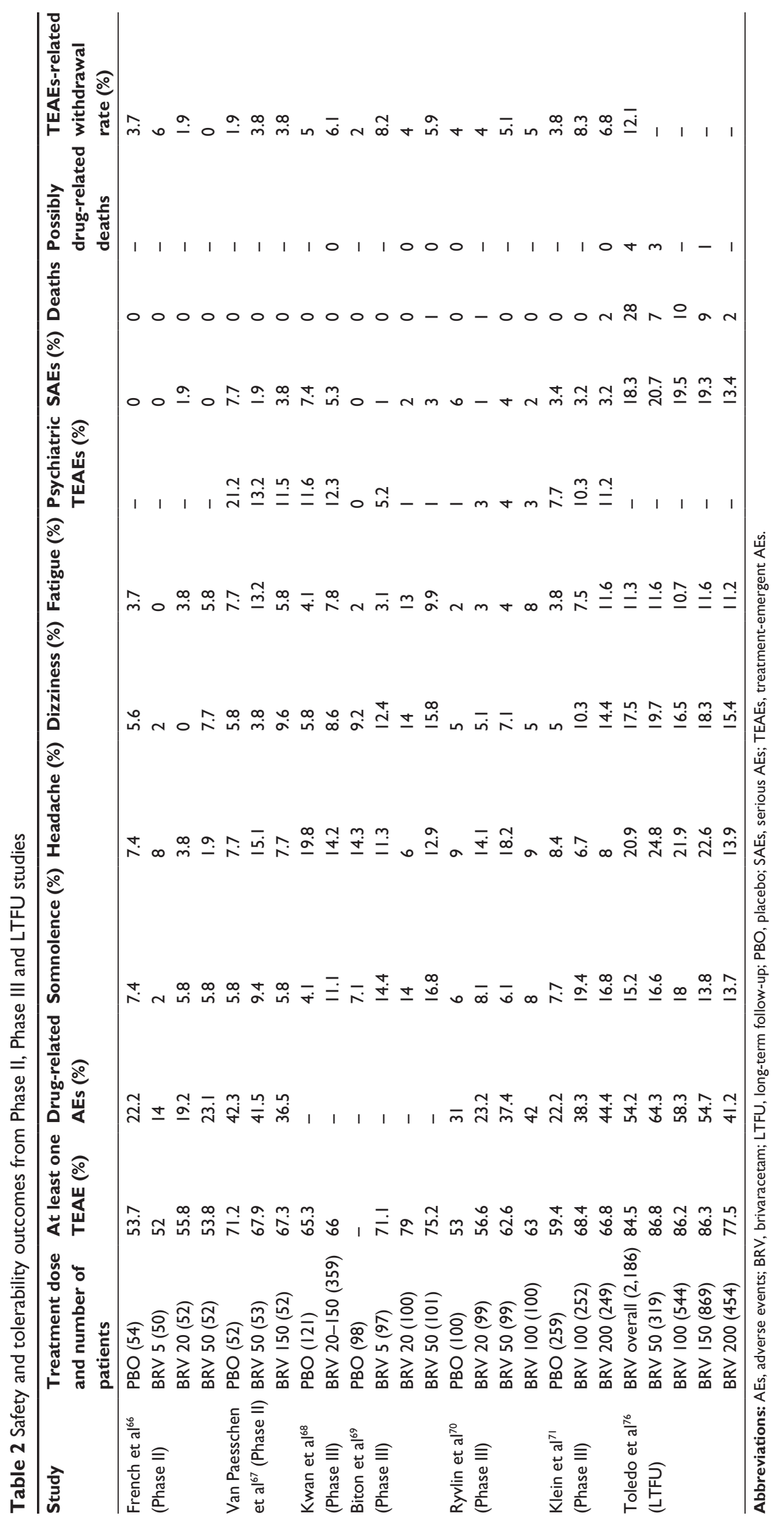


and $1.9 \%$ for depression. The TEAEs significantly related to BRV were irritability, fatigue, somnolence and dizziness. Irritability, insomnia, depression and anxiety, which were the most commonly described psychiatric AEs, occurred in $2 \%$ to almost $3 \%$ of the BRV-treated participants. No clinically significant modifications from baseline were reported in blood chemistry, urinary parameters, vital signs, electrocardiogram (ECG) findings and physical and neurological examination. Four participants died during two trials. ${ }^{69-71}$ The first patient, ${ }^{69}$ who was receiving BRV $50 \mathrm{mg} /$ day, died 2 weeks after he had discontinued the drug because of a subarachnoid hemorrhage, while another participant, taking BRV $20 \mathrm{mg} /$ day, had a cardiorespiratory arrest following an epileptic crisis. ${ }^{70}$ Two more participants died, while receiving BRV $200 \mathrm{mg} /$ day; one death was unexplained and the other one died during an epileptic attack. ${ }^{71}$ However, no deaths were judged by investigators to be BRV treatment related.

\section{Long-term extension studies}

Data deriving from a pooled analysis ${ }^{76}$ including Phase IIb, ${ }^{66,67}$ Phase III ${ }^{68-71}$ and associated LTFU studies were consistent with those reported earlier. More in detail, 1,848 (84.5\%) out of 2,186 patients treated with BRV 50-200 mg/day, experienced at least one TEAE, which was considered to be drug related in 1,184 (54.2\%). There was no evidence that TEAE incidence was dose dependent. The most common TEAE for BRV 50-150 mg/day was headache (13.9\%-24.8\%); for BRV $200 \mathrm{mg} /$ day it was dizziness (15.4\%). Other TEAEs (dizziness, somnolence, nasopharyngitis, fatigue and epilepsy) occurred in $10 \%$ of the treated population. Of 2,186 patients, $264(12.1 \%)$ were forced to discontinue treatment because of TEAEs (convulsions $1.4 \%$, pregnancy $0.9 \%$, somnolence $0.7 \%$, depression $0.6 \%$, dizziness $0.6 \%$, fatigue $0.5 \%$, suicide ideation $0.5 \%$ and suicide attempt $0.5 \%$ ). The most common psychiatric AEs were depression (7.1\%), insomnia (6.2\%), irritability (5.2\%), anxiety (4.9\%), suicide ideation $(2.0 \%)$, depressed mood (1.8\%), aggression (1.7\%), nervousness $(1.6 \%)$ and sleep disorders (1.6\%). Serious AEs (SAEs) occurred in $401(18.3 \%)$ patients and resulted to be treatment related in 95 (4.3\%). Of the 28 deaths reported (1.3\%), four could be possibly related to drug therapy. Two patients, aged 30 and 50 years, experienced a sudden unexpected death in epilepsy (SUDEP) while receiving BRV $50 \mathrm{mg} /$ day for 8.2 and 42.2 months, respectively. A potential SUDEP event was described also for a young woman aged 21 years, who was taking BRV $50 \mathrm{mg}$ /day when brain hypoxia occurred. Finally, a 20-year-old man committed suicide after a 24.8-month treatment period with BRV $150 \mathrm{mg} /$ day. To date, no evident idiosyncratic AEs have been identified.

Results from LTFU studies relative to seizure outcome and safety and tolerability are summarized in Table 3A and B.

\section{BRV IV formulation}

Recently, a Phase III, randomized trial ${ }^{75}$ was conducted to assess the safety and tolerability of add-on BRV as IV infusion or bolus in patients affected by epilepsy. The study, involving 105 adults aged 16-70 years with focal or generalized epilepsy, comprised a baseline period of 7 days, followed by a 7-day double-blind run-in period, in which patients received oral BRV $200 \mathrm{mg}$ /day or PBO. Finally, participants underwent a 4.5-day open-label evaluation period in which they received IV BRV, administered as a 15-min infusion or 2-min bolus at $100 \mathrm{mg}$ twice daily, for nine doses. Patients were randomized to receive $\mathrm{PBO} / \mathrm{BRV}$ bolus, $\mathrm{PBO} /$ BRV infusion, BRV/BRV bolus and BRV/BRV infusion. Participants who completed the study were offered entry into an LTFU study or down-titration. A similar incidence of TEAE was reported for each treatment arm. No relevant differences were noted in TEAE incidence for IV BRV used de novo (after PBO - initiation group) or as replacement for oral administration (after oral BRV - conversion group). The same incidence of AEs was reported also for IV BRV administered as bolus or infusion. The most frequently described AEs were somnolence (29.5\%) and dizziness (14.3\%), with somnolence being the most common drug-related TEAE. Severe TEAEs (nausea, vertigo) occurred only in one patient

Table 3A Seizure outcomes from LTFU studies ${ }^{66-71,76}$

\begin{tabular}{|c|c|c|c|c|}
\hline Seizure outcome & I-3 months & 58-60 months & & \\
\hline Median percentage reduction from baseline in POS/28 days & $43.1 \%$ & $77.0 \%$ & & \\
\hline \multirow[t]{2}{*}{$\geq 50 \%$ responder rate } & $43.5 \%$ & $71 \%$ & & \\
\hline & 6 months & 12 months & 24 months & 60 months \\
\hline Seizure-freedom rates & $4.9 \%$ & $4.2 \%$ & $3.0 \%$ & $3.3 \%$ \\
\hline Retention rates & $71.0 \%$ & $79.8 \%$ & $68.1 \%$ & $54.4 \%$ \\
\hline
\end{tabular}

Note: Exposure time to BRV modal dose $50-200 \mathrm{mg} /$ day.

Abbreviations: BRV, brivaracetam; LTFU, long-term follow-up; POS, partial-onset seizure. 
Table 3B Safety and tolerability of BRV during LTFU studies: focus on TEAE-related withdrawal rate, psychiatric side effects and causes of death

\begin{tabular}{|c|c|c|c|c|c|}
\hline Patients, n (\%) & BRV overall $(2,186)$ & BRV 50 (3 I9) & BRV I $00(544)$ & BRV I50 (869) & BRV $200(454)$ \\
\hline Drug-related TEAEs & $\mathrm{I}, 184(54.2)$ & $205(64.3)$ & $317(58.3)$ & $475(54.7)$ & $187(4 \mid .2)$ \\
\hline TEAEs-related withdrawal rate (\%) & $264(12.1)$ & $70(21.9)$ & $79(14.5)$ & $73(8.4)$ & $42(9.3)$ \\
\hline Convulsion & $31(1.4)$ & - & - & - & - \\
\hline Pregnancy & $19(0.9)$ & - & - & - & - \\
\hline Somnolence & $16(0.7)$ & - & - & - & - \\
\hline Depression & $14(0.6)$ & - & - & - & - \\
\hline Dizziness & $14(0.6)$ & - & - & - & - \\
\hline Fatigue & $12(0.5)$ & - & - & - & - \\
\hline Suicidal ideation & II (0.5) & - & - & - & - \\
\hline Suicide attempt & $10(0.5)$ & - & - & - & - \\
\hline Psychiatric/behavioral side effects ( $\geq 1 \%$ ) & - & - & - & - & - \\
\hline Depression & $156(7.1)$ & - & & & \\
\hline Insomnia & $135(6.2)$ & - & - & - & - \\
\hline Irritability & $114(5.2)$ & - & - & - & - \\
\hline Anxiety & $107(4.9)$ & - & - & - & - \\
\hline Suicidal ideation & $43(2)$ & - & - & - & - \\
\hline Depressed mood & $39(1.8)$ & - & - & - & - \\
\hline Aggression & $38(1.7)$ & - & - & - & - \\
\hline Nervousness & $36(1.6)$ & - & - & - & - \\
\hline Sleep disorders & $34(1.6)$ & - & - & - & - \\
\hline Suicide attempt & $13(0.6)$ & - & - & - & - \\
\hline Most common SAEs ( $\geq 0.5 \%)$ & $40 \mathrm{I}(18.3)$ & $66(20.7)$ & $106(19.5)$ & $168(19.3)$ & $61(13.4)$ \\
\hline Convulsion & $56(2.6)$ & - & - & - & - \\
\hline Status epilepticus & $20(0.9)$ & - & - & - & - \\
\hline Pneumonia & $12(0.5)$ & - & - & - & - \\
\hline Epilepsy & $13(0.6)$ & - & - & - & - \\
\hline Suicidal ideation & $12(0.5)$ & - & - & - & - \\
\hline Suicide attempt & $12(0.5)$ & - & - & - & - \\
\hline Fall & $10(0.5)$ & - & - & - & - \\
\hline Drug-related SAEs & $95(4.3)$ & $19(6.0)$ & $29(5.3)$ & $35(4.0)$ & $12(2.6)$ \\
\hline Deaths & $28(1.3)$ & $7(2.2)$ & $10(1.8)$ & $9(1.0)$ & $2(0.4)$ \\
\hline Possibly BRV related & $4(14.3)$ & 3 & - & 1 & - \\
\hline SUDEP & 3 & 3 & - & - & - \\
\hline Hypertensive heart disease & I & - & - & - & - \\
\hline Brain hypoxia & I & - & - & - & - \\
\hline Pulmonary congestion & I & - & - & - & - \\
\hline Death & I & - & - & - & - \\
\hline Sudden death & I & - & - & - & - \\
\hline Myocardial infarction & 3 & - & - & - & - \\
\hline Completed suicide & 2 & - & I & 1 & - \\
\hline
\end{tabular}

Note: Data from Toledo et al. ${ }^{76}$

Abbreviations: BRV, brivaracetam; LTFUs, long-term follow-up studies; SAE, serious adverse event; SUDEP, sudden unexpected death in epilepsy; TEAE, treatmentemergent adverse event.

and were considered to be drug related. There were no serious TEAEs, and no deaths were reported. Two patients interrupted the trial: one patient in the $\mathrm{PBO} / \mathrm{BRV}$ bolus arm because of rash occurring during the run-in period, before receiving any dose of $\mathrm{BRV}$. The other patient belonged to $\mathrm{PBO} / \mathrm{BRV}$ infusion arm; after he had received six doses of $\mathrm{BRV}$, he was forced to discontinue the treatment because of anxiety. Injection-related TEAEs during the IV BRV period occurred with a low frequency for both bolus and infusion groups (9.6 and $11.5 \%$, respectively) and consisted of erythema, injection/infusion-site pain. They never required treatment discontinuation. ${ }^{75}$

Table 4 summarizes differences and similarities of the main trials on LCM, PER, ESL and BRV.

\section{Patient-focused perspectives}

One of the most important goals of the epilepsy management is to achieve seizure freedom, but health-related quality of life (HRQoL) is also important and should be considered a crucial aspect in the evaluation of treatment success. 
Table 4 Comparison of $\geq 50 \%$ responder rate, seizure-free percentage, and TEAEs between LCM, ESL, BRV, and PER

\begin{tabular}{|c|c|c|c|c|c|c|}
\hline AED & RCTs & ITT & $\begin{array}{l}\text { Treatment dose ( } \mathrm{mg} / \mathrm{day}) \\
\text { and number of patients }\end{array}$ & $\geq \mathbf{5 0} \%$ responder rate & Seizure freedom (\%) & TEAEs \\
\hline \multirow[t]{6}{*}{ LCM } & Halasz et $\mathrm{al}^{79}$ & 485 & $200(160)$ & $35.0(200 \mathrm{mg})$ & 3.6 (200 mg) & $96 / 163(200 \mathrm{mg})$ \\
\hline & & & $400(158)$ & 40.5 (400 mg) & 2.4 (400 mg) & I I6/I59 (400 mg) \\
\hline & & & PBO (I59) & 25.8 (PBO) & 25.8 (PBO) & 43/I63 (PBO) \\
\hline & Chung et $\mathrm{al}{ }^{80}$ & 405 & $400(104)$ & $38.3(400 \mathrm{mg})$ & $2.5(400 \mathrm{mg})$ & $42.0(400 \mathrm{mg})$ \\
\hline & & & $600(97)$ & $41.2(600 \mathrm{mg})$ & 8.1 (600 mg) & $50.0(600 \mathrm{mg})$ \\
\hline & & & PBO (104) & $0.0(\mathrm{PBO})$ & $0.0(\mathrm{PBO})$ & 10.6 (PBO) \\
\hline \multirow[t]{7}{*}{ ESL } & Elger et $\mathrm{a}^{81}$ & 295 & $400(100)$ & 23 & I 6.7 (400 mg) & 44.0 (ESL 400 mg) \\
\hline & & & $800(98)$ & 34 & 40.05 (800 mg) & 50.0 (ESL 800 mg) \\
\hline & & & $\mathrm{I}, 200(102)$ & 47 & $37.6(1,200 \mathrm{mg})$ & 60.8 (ESL I,200 mg) \\
\hline & & & PBO (102) & 20 & $12.0(\mathrm{PBO})$ & 31.4 (PBO) \\
\hline & Sperling et $\mathrm{al}^{30}$ & 640 & $800(215)$ & 30.5 & $30.5(800 \mathrm{mg})$ & 67.1 (800 mg) \\
\hline & & & $\mathrm{I}, 200(205)$ & 42.5 & $42.6(1,200 \mathrm{mg})$ & $77.6(1,200 \mathrm{mg})$ \\
\hline & & & PBO (220) & 23.1 & 23.1 (PBO) & 55.8 (PBO) \\
\hline \multirow[t]{11}{*}{ BRV } & Kwan et $\mathrm{al}^{68}$ & 480 & BRV 20-I50 (359) & 32.0 (5 mg) & $8.0(5)$ & 66.0 (BRV) \\
\hline & & & $\mathrm{PBO}(12 \mathrm{I})$ & $44.2(20 \mathrm{mg})$ & $7.7(20)$ & $65.3(\mathrm{PBO})$ \\
\hline & & & & $55.8(50 \mathrm{mg})$ & $7.7(50)$ & - \\
\hline & & & & $16.7(\mathrm{PBO})$ & 1.9 (PBO) & - \\
\hline & Ryvlin et $\mathrm{al}^{70}$ & 398 & BRV 20 (99) & 20 & 0 & 56.6 (BRV $20 \mathrm{mg}$ ) \\
\hline & & & BRV 50 (99) & 27.3 & 2 & 62.6 (BRV $50 \mathrm{mg}$ ) \\
\hline & & & BRV $100(100)$ & 27.3 & 0 & 63.0 (BRV $100 \mathrm{mg})$ \\
\hline & & & PBO $(100)$ & 36 & 4 & $53.0(\mathrm{PBO})$ \\
\hline & Klein et $\mathrm{al}^{71}$ & 760 & PBO (259) & 21.6 & 0.8 & $67.6(\mathrm{BRV})$ \\
\hline & & & BRV I00 (252) & 38.9 & 5.2 & 59.4 (PBO) \\
\hline & & & BRV 200 (249) & 37.8 & 4 & - \\
\hline \multirow[t]{6}{*}{ PER } & Steinhoff et al ${ }^{45}$ & $\mathrm{I}, 480$ & $2,4,8$ or $12 \mathrm{mg} /$ day $(1,038)$ & 28.5 (4 mg) & $4.4(4 \mathrm{mg})$ & 77.5 (PER) \\
\hline & & & PBO (442) & $35.3(8 \mathrm{mg})$ & $3.5(8 \mathrm{mg})$ & 66.5 (PBO) \\
\hline & & & & 35.0 (I2 mg) & $4.1(12 \mathrm{mg})$ & - \\
\hline & & & & 19.3 (PBO) & 1.0 (PBO) & - \\
\hline & Lagae et $\mathrm{a}^{82}$ & 133 & Up to $12 \mathrm{mg} /$ day (85 PBO [48]) & 59.0 (PER) & 23.7 (PER) & 68.2 (PER) \\
\hline & & & & 16.3 (PBO) & $16.3(\mathrm{PBO})$ & 41.7 (PBO) \\
\hline
\end{tabular}

Abbreviations: BRV, brivaracetam; ESL, eslicarbazepine; ITT, intention-to-treat; LCM, lacosamide; PBO, placebo; PER, perampanel; RCTs, randomized controlled trials; TEAE, treatment-emergent adverse effect; AED, antiepileptic drug.

Variables influencing HRQoL are TEAE rate due to antiepileptic therapy, depression, anxiety, perceived stigma of epilepsy and consequent lack of independence. In this regard, HRQoL was assessed in a large pooled analysis ${ }^{76}$ including patients from Phase IIb, III and LTFU studies, using the Quality of Life in Epilepsy Inventory-31 (QOLIE-31P), a patient-reported instrument evaluating seven subscales. In the efficacy population (BRV modal doses 50-200 mg/day, $\mathrm{n}=1,836$ ), improvements in HRQoL were reported in $45 \%$ of patients from month 2 , with a tendency to increase until month 42 for patients who entered LTFU studies. In particular, for the first 42 months of treatment, the greatest improvements were seen for seizure worry and daily activities/social functioning subscales, which led to clinically significant improvements from baseline in 59 and $55 \%$ of patients, respectively. Lower improvements were observed at subsequent time points (eg, month 48), probably due to a change in population composition, which became more heterogeneous with respect to the original core studies, and a reduced patient number. In fact, at month 42, the majority of the population consisted of patients who responded well to BRV and continued to LTFU studies; while, over time, a critically lower number of patients was available for HRQoL assessments, due to protocol-specified completion of QOLIE-31P which was limited to 24 months for patients enrolled later. A meaningful improvement in daily activities/social functioning was observed during $\geq 42$ months of BRV administration. Overall data confirm a sustained effect of BRV, used as long-term ( $\geq 8$ years) treatment, in improving HRQoL without any deterioration in safety and tolerability.

According to these data, adjunctive BRV in adults showed high adherence to treatment over time; in fact, patients from core and LTFU studies receiving BRV 50-200 mg/day showed retention rates of 91.0, 79.8, 68.1 and 54.4\% at month $6,12,24$ and 60 , respectively. $^{76}$

\section{Most appropriate patient profiles for treatment with BRV}

Adjunctive BRV proved to be effective in reducing seizure frequency in adults aged 16-80 years with POS at the dose 
range of 50-200 mg/day, in Phase IIb, Phase III and LTFU studies. On the other hand, BRV seems to provide no additional benefit when administered with concomitant LEV, probably due to competition for the same binding sites. Nevertheless, BRV was able to provide good results in patients who previously discontinued LEV because of TEAEs, rather than due to lack of efficacy. In fact, as reported in a small Phase III study including adults with refractory epilepsy, a decrease in behavioral AE rate was observed when patients switched from LEV to BRV. ${ }^{77}$

Overall, BRV showed a favorable safety and tolerability profile as supported by high retention rates across all BRV doses, and low incidence of TEAEs, which were of mildto-moderate intensity. No idiosyncratic AEs were reported. BRV tolerability, safety and efficacy were assessed in a pooled analysis involving patients aged $\geq 65$ years from the three fixed-dose Phase III studies, showing results consistent with those observed in larger populations mentioned earlier and, therefore, suggesting that BRV is a suitable add-on treatment also in the elderly. ${ }^{78}$

Recently, the efficacy, tolerability and safety of add-on BRV have been investigated in adult patients with Unverricht-Lundborg disease in two prospective, doubleblind, Phase III trials ${ }^{60}$ in which patients were randomized to receive BRV or PBO; these studies failed to show a statistically significant effect of adjunctive BRV on action myoclonus score compared to PBO.

Interestingly, thanks to its rapid predicted blood-brain permeability and fast brain SV2A occupancy observed in preclinical studies, ${ }^{62}$ IV BRV formulation may have a role in the treatment of emergency situations, such as status epilepticus. However, as yet, there is no experience in this field.

To date, BRV has not yet been evaluated as monotherapy or in comparison with other new AEDs, neither during pregnancy nor during lactation. Concerning children, there is an ongoing Phase III study whose results are still unpublished.

\section{Place in therapy and conclusion}

BRV was approved in the EU in January 2016 and in the US in February 2016 as adjunctive therapy for the treatment of POS in patients older than 16 years of age. ${ }^{60}$ Hence, it is undoubtedly a drug included among the therapeutic options for partial seizures both as adjunctive therapy and, likely, as monotherapy. However, its place in therapy remains to be defined due to the lack of head-to-head clinical studies comparing BRV with other AEDs and to the need for broader real-world clinical experience. Thanks to a low incidence of TEAEs and idiosyncratic adverse effects, BRV seems a suitable add-on treatment also for the elderly.
The IV BRV formulation could be suitable for the treatment of emergency situations, such as status epilepticus. However, as yet, there is no experience in this field.

Finally, it could be considered as a potential alternative to LEV in the presence of adverse effects, especially behavioral side effects. Pediatric clinical data with BRV are expected within the next year.

\section{Disclosure}

The authors report no conflicts of interest in this work.

\section{References}

1. Engel J Jr; for International League Against Epilepsy (ILAE). A proposed diagnostic scheme for people with epileptic seizures and with epilepsy: report of the ILAE Task Force on Classification and Terminology. Epilepsia. 2001;42(6):796-803.

2. Berg AT, Berkovic SF, Brodie MJ, et al. Revised terminology and concepts for organization of seizures and epilepsies: report of the ILAE Commission on Classification and Terminology, 2005-2009. Epilepsia. 2010;51(4):676-685.

3. Sillanpää M. Long-term outcome of epilepsy. Epileptic Disord. 2000; 2(2):79-88.

4. Olafsson E, Ludvigsson P, Gudmundsson G, Hesdorffer D, Kjartansson O, Hauser WA. Incidence of unprovoked seizures and epilepsy in Iceland and assessment of the epilepsy syndrome classification: a prospective study. Lancet Neurol. 2005;4(10):627-634.

5. Astradsson A, Olafsson E, Ludvigsson P, Björgvinsson H, Hauser WA. Rolandic epilepsy: an incidence study in Iceland. Epilepsia. 1998; 39(8):884-886.

6. Burneo JG, Tellez-Zenteno J, Wiebe S. Understanding the burden of epilepsy in Latin America: a systematic review of its prevalence and incidence. Epilepsy Res. 2005;66(1-3):63-74.

7. Mac TL, Tran DS, Quet F, Odermatt P, Preux PM, Tan CT. Epidemiology, aetiology, and clinical management of epilepsy in Asia: a systematic review. Lancet Neurol. 2007;6(6):533-543.

8. Morris GL. Gabapentin. Epilepsia. 1999;40(suppl 5):S63-S70.

9. Rating D, Wolf C, Bast T. Sulthiame as monotherapy in children with benign childhood epilepsy with centrotemporal spikes: a 6-month randomized, double-blind, placebo-controlled study. Sulthiame Study Group. Epilepsia. 2000;41(10):1284-1288.

10. Glauser T, Ben-Menachem E, Bourgeois B, et al. ILAE treatment guidelines: evidence-based analysis of antiepileptic drug efficacy and effectiveness as initial monotherapy for epileptic seizures and syndromes. Epilepsia. 2006;47(7):1094-1120.

11. Wirrell E, Sherman EM, Vanmastrigt R, Hamiwka L. Deterioration in cognitive function in children with benign epilepsy of childhood with central temporal spikes treated with sulthiame. J Child Neurol. 2008; 23(1):14-21

12. Tzitiridou M, Panou T, Ramantani G, Kambas A, Spyroglou K, Panteliadis C. Oxcarbazepine monotherapy in benign childhood epilepsy with centrotemporal spikes: a clinical and cognitive evaluation. Epilepsy Behav. 2005;7(3):458-467.

13. Coppola G, Franzoni E, Verrotti A, et al. Levetiracetam or oxcarbazepine as monotherapy in newly diagnosed benign epilepsy of childhood with centrotemporal spikes (BECTS): an open-label, parallel group trial. Brain Dev. 2007;29(5):281-284. Epub 2006 Oct 20.

14. Jaruthamsophon K, Sripo T, Sukasem C, Limprasert P. Comparison of a new in-house and three published HLA-B*15:02 screening methods for prevention of carbamazepine-induced severe drug reactions. PLoS One. 2016;11(5): 0155907.

15. Nunes VD, Sawyer L, Neilson J, Sarri G, Cross JH. Diagnosis and management of the epilepsies in adults and children: summary of updated NICE guidance. BMJ. 2012;344:e281. 
16. de Silva M, MacArdle B, McGowan M, et al. Randomised comparative monotherapy trial of phenobarbitone, phenytoin, carbamazepine, or sodium valproate for newly diagnosed childhood epilepsy. Lancet. 1996;347(9003):709-713.

17. Wheless JW, Clarke DF, Arzimanoglou A, Carpenter D. Treatment of pediatric epilepsy: European expert opinion. Epileptic Disord. 2007;9(4):353-412.

18. Canadian Study Group for Childhood Epilepsy. Clobazam has equivalent efficacy to carbamazepine and phenytoin as monotherapy for childhood epilepsy. Epilepsia. 1998;39(9):952-959.

19. Michael B, Marson AG. Clobazam as an add-on in the management of refractory epilepsy. Cochrane Database Syst Rev. 2008;6(2): CD004154.

20. Piña-Garza JE, Levisohn P, Gucuyener K, et al. Adjunctive lamotrigine for partial seizures in patients aged 1 to 24 months. Neurology. 2008;70(22 pt 2):2099-2108.

21. Piña-Garza JE, Nordli DR Jr, Rating D, et al; for Levetiracetam N01009 Study Group. Adjunctive levetiracetam in infants and young children with refractory partial-onset seizures. Epilepsia. 2009;50(5): 1141-1149.

22. Brodie MJ, Rosenfeld WE, Vazquez B, et al. Rufinamide for the adjunctive treatment of partial seizures in adults and adolescents: a randomized placebo-controlled trial. Epilepsia. 2009;50(8): 1899-1909

23. Elger CE, Stefan H, Mann A, Narurkar M, Sun Y, Perdomo C. A 24-week multicenter, randomized, double-blind, parallel-group, doseranging study of rufinamide in adults and adolescents with inadequately controlled partial seizures. Epilepsy Res. 2010;88(2-3):255e63.

24. Biton V, Krauss G, Vasquez-Santana B, et al. A randomized, doubleblind, placebo-controlled, parallel-group study of rufinamide as adjunctive therapy for refractory partial-onset seizures. Epilepsia. 2011; 52(2):234e42.

25. Moavero R, Cusmai R, Specchio N, et al. Rufinamide efficacy and safety as adjunctive treatment in children with focal drug resistant epilepsy: the first Italian prospective study. Epilepsy Res. 2012;102(1-2):94e9.

26. Coppola G, Zamponi N, Kluger G, et al. Rufinamide for refractory focal seizures: an open-label, multicenter European study. Seizure. 2013;22(1):33e6.

27. Coppola G, Grosso S, Franzoni E, et al. Rufinamide in refractory childhood epileptic encephalopathies other than Lennox-Gastaut syndrome. Eur J Neurol. 2011;18(2):246e51.

28. Cusmai R, Verrotti A, Moavero R, et al. Rufinamide for the treatment of refractory epilepsy secondary to neuronal migration disorders. Epilepsy Res. 2014;108(3):542e6.

29. Gil-Nagel A, Elger C, Ben-Menachem E, et al. Efficacy and safety of eslicarbazepine acetate as add-on treatment in patients with focal-onset seizures: integrated analysis of pooled data from double-blind phase III clinical studies. Epilepsia. 2013;54(1):98-107.

30. Sperling MR, Abou-Khalil B, Harvey J, et al; for 304 Study Team. Eslicarbazepine acetate as adjunctive therapy in patients with uncontrolled partial-onset seizures: results of a phase III, double-blind, randomized, placebo-controlled trial. Epilepsia. 2015;56(2):244-253.

31. Hufnagel A, Ben-Menachem E, Gabbai AA, Falcão A, Almeida L, Soares-da-Silva P. Long-term safety and efficacy of eslicarbazepine acetate as adjunctive therapy in the treatment of partial-onset seizures in adults with epilepsy: results of a 1-year open-label extension study. Epilepsy Res. 2013;103(2-3):262-269.

32. Villanueva V, Serratosa JM, Guillamón E, et al. Long-term safety and efficacy of eslicarbazepine acetate in patients with focal seizures: results of the 1-year ESLIBASE retrospective study. Epilepsy Res. 2014; 108(7):1243-1252.

33. Correia FD, Freitas J, Magalhães R, et al. Two-year follow-up with eslicarbazepine acetate: a consecutive, retrospective, observational study. Epilepsy Res. 2014;108(8):1399-1405.

34. Sperling MR, French J, Jacobson MP, et al; for Study 045 and 046 Investigators. Conversion to eslicarbazepine acetate monotherapy: a pooled analysis of 2 phase III studies. Neurology. 2016;86(12):1095-1102.
35. Schmid E, Kuchukhidze G, Kirschner M, et al. Overnight switching from oxcarbazepine to eslicarbazepine acetate: an observational study. Acta Neurol Scand. Epub 2016 Jul 22.

36. Almeida L, Minciu I, Nunes T, et al. Pharmacokinetics, efficacy, and tolerability of eslicarbazepine acetate in children and adolescents with epilepsy. J Clin Pharmacol. 2008;48(8):966-977.

37. Tambucci R, Basti C, Maresca M, Coppola G, Verrotti A. Update on the role of eslicarbazepine acetate in the treatment of partial-onset epilepsy. Neuropsychiatr Dis Treat. 2016;12:1251-1260.

38. Borzì G, Di Gennaro G, Schmitt FC, et al. Lacosamide in patients with temporal lobe epilepsy: an observational multicentric open-label study. Epilepsy Behav. 2016;58:111-114.

39. Zadeh WW, Escartin A, Byrnes W, et al; for SP0954 Study Group. Efficacy and safety of lacosamide as first add-on or later adjunctive treatment for uncontrolled partial-onset seizures: a multicentre openlabel trial. Seizure. 2015;31:72-79.

40. Runge U, Arnold S, Brandt C, et al. A noninterventional study evaluating the effectiveness and safety of lacosamide added to monotherapy in patients with epilepsy with partial-onset seizures in daily clinical practice: The VITOBA study. Epilepsia. 2015;56(12):1921-1930.

41. Wechsler RT, Li G, French J, et al; for ALEX-MT Study Group. Conversion to lacosamide monotherapy in the treatment of focal epilepsy: results from a historical-controlled, multicenter, double-blind study. Epilepsia. 2014;55(7):1088-1098.

42. Lattanzi S, Cagnetti C, Foschi N, Provinciali L, Silvestrini M. Lacosamide monotherapy for partial onset seizures. Seizure. 2015;27: 71-74.

43. Giráldez BG, Toledano R, García-Morales I, et al. Long-term efficacy and safety of lacosamide monotherapy in the treatment of partial-onset seizures: a multicenter evaluation. Seizure. 2015;29:119-122.

44. Foldvary-Schaefer N, Fong JS, Morrison S, Wang L, Bena J. Lacosamide tolerability in adult patients with partial-onset seizures: impact of planned reduction and mechanism of action of concomitant antiepileptic drugs. Epilepsy Behav. 2016;57(pt A):155-160.

45. Steinhoff BJ, Ben-Menachem E, Ryvlin P, et al. Efficacy and safety of adjunctive perampanel for the treatment of refractory partial seizures: a pooled analysis of three phase III studies. Epilepsia. 2013;54(8): 1481-1489.

46. Meador KJ, Yang H, Pina-Garza JE, Laurenza A, Kumar D, Wesnes KA. Cognitive effects of adjunctive perampanel for partial-onset seizures: a randomized trial. Epilepsia. 2016;57(2):243-251.

47. Winesett SP, Bessone SK, Kossoff EH. The Ketogenic diet in pharmacoresistant childhood epilepsy. Expert Rev Neurother. 2015;15(6): 621-628.

48. Tecoma ES, Iragui VJ. Vagus nerve stimulation use and effect in epilepsy: what have we learned? Epilepsy Behav. 2006;8(1):127-136.

49. Morell M. Brain stimulation for epilepsy: can scheduled or responsive neurostimulation stop seizures? Curr Opin Neurol. 2006;19(2): 164-168.

50. Theodore WH, Hunter K, Chen R, et al. Transcranial magnetic stimulation for the treatment of seizures: a controlled study. Neurology. 2002;59(4):560-562.

51. Kaminski RM, Matagne A, Leclercq K, et al. SV2A protein is a broadspectrum anticonvulsant target: functional correlation between protein binding and seizure protection in models of both partial and generalized epilepsy. Neuropharmacology. 2008;54(4):715-720.

52. Wasterlain CG, Suchomelova L, Matagne A, et al. Short-term and longterm effects of brivaracetam in an animal model of status epilepticus. Epilepsia. 2009;50(supp110):13.

53. Matagne A, Margineanu DG, Kenda B, Michel P, Klitgaard H. Anticonvulsive and anti-epileptic properties of brivaracetam (ucb 34714), a high-affinity ligand for the synaptic vesicle protein, SV2A. $\mathrm{Br} J$ Pharmacol. 2008;154(8):1662-1671.

54. Gillard M, Fuks B, Leclercq K, Matagne A. Binding characteristics of brivaracetam, a selective, high affinity SV2A ligand in rat, mouse and human brain: relationship to anti-convulsant properties. Eur $J$ Pharmacol. 2011;664(1-3):36-44. 
55. Yang X, Bognar J Jr, He T, et al. Brivaracetam augments short-term depression and slows vesicle recycling. Epilepsia. 2015;56(12): 1899-1909.

56. Zona C, Pieri M, Carunchio I, Curcio L, Klitgaard H, Margineanu DG. Brivaracetam (ucb 34714) inhibits $\mathrm{Na}(+$ ) current in rat cortical neurons in culture. Epilepsy Res. 2010;88(1):46-54.

57. Niespodziany I, André VM, Leclère N, Hanon E, Ghisdal P, Wolff C. Brivaracetam differentially affects voltage-gated sodium currents without impairing sustained repetitive firing in neurons. CNS Neurosci Ther. 2015;21(3):241-251.

58. Sargentini-Maier ML, Rolan P, Connell J, et al. The pharmacokinetics, CNS pharmacodynamics and adverse event profile of brivaracetam after single increasing oral doses in healthy males. Br J Clin Pharmacol. 2007;63(6):680-688

59. Rolan P, Sargentini-Maier ML, Pigeolet E, Stockis A. The pharmacokinetics, CNS pharmacodynamics and adverse event profile of brivaracetam after multiple increasing oral doses in healthy men. $\mathrm{Br}$ Clin Pharmacol. 2008;66(1):71-75.

60. Kälviäinen R, Genton P, Andermann E, et al. Brivaracetam in Unverricht-Lundborg disease (EPM1): results from two randomized, doubleblind, placebo-controlled studies. Epilepsia. 2016;57(2):210-221.

61. Sargentini-Maier ML, Espié P, Coquette A, Stockis A. Pharmacokinetics and metabolism of 14C-brivaracetam, a novel SV2A ligand, in healthy subjects. Drug Metab Dispos. 2008;36(1):36-45.

62. Nicolas JM, Hannestad J, Holden D, et al. Brivaracetam, a selective high-affinity synaptic vesicle protein 2A (SV2A) ligand with preclinical evidence of high brain permeability and fast onset of action. Epilepsia. 2016;57(2):201-209.

63. Stockis A, Watanabe S, Rouits E, Matsuguma K, Irie S. Brivaracetam single and multiple rising oral dose study in healthy Japanese participants: influence of CYP2C19 genotype. Drug Metab Pharmacokinet. 2014;29(5):394-399

64. Sargentini-Maier ML, Sokalski A, Boulanger P, Jacobs T, Stockis A. Brivaracetam disposition in renal impairment. J Clin Pharmacol. 2012; 52(12):1927-1933.

65. Stockis A, Sargentini-Maier ML, Horsmans Y. Brivaracetam disposition in mild to severe hepatic impairment. J Clin Pharmacol. 2013; 53(6):633-641.

66. French JA, Costantini C, Brodsky A, von Rosenstiel P; N01193 Study Group. Adjunctive brivaracetam for refractory partial-onset seizures: a randomized, controlled trial. Neurology. 2010;75(6):519-525.

67. Van Paesschen W, Hirsch E, Johnson M, Falter U, von Rosenstiel P. Efficacy and tolerability of adjunctive brivaracetam in adults with uncontrolled partial-onset seizures: a phase IIb, randomized, controlled trial. Epilepsia. 2013;54(1):89-97.

68. Kwan P, Trinka E, Van Paesschen W, Rektor I, Johnson ME, Lu S Adjunctive brivaracetam for uncontrolled focal and generalized epilepsies: results of a phase III, double-blind, randomized, placebocontrolled, flexible-dose trial. Epilepsia. 2014;55(1):38-46.

69. Biton V, Berkovic SF, Abou-Khalil B, Sperling MR, Johnson ME, Lu S Brivaracetam as adjunctive treatment for uncontrolled partial epilepsy in adults: a phase III randomized, double-blind, placebo-controlled trial. Epilepsia. 2014;55(1):57-66.
70. Ryvlin P, Werhahn KJ, Blaszczyk B, Johnson ME, Lu S. Adjunctive brivaracetam in adults with uncontrolled focal epilepsy: results from a double-blind, randomized, placebo-controlled trial. Epilepsia. 2014; 55(1):47-56.

71. Klein P, Schiemann J, Sperling MR, et al. A randomized, double-blind, placebo-controlled, multicenter, parallel-group study to evaluate the efficacy and safety of adjunctive brivaracetam in adult patients with uncontrolled partial-onset seizures. Epilepsia. 2015;56(12):1890-1898.

72. Ma J, Huang S, You C. Adjunctive brivaracetam for patients with refractory partial seizures: a meta-analysis of randomized placebo-controlled trials. Epilepsy Res. 2015;114:59-65.

73. Tian X, Yuan M, Zhou Q, Wang X. The efficacy and safety of brivaracetam at different doses for partial-onset epilepsy: a meta-analysis of placebo-controlled studies. Expert Opin Pharmacother. 2015;16(12): 1755-1767.

74. Lattanzi S, Cagnetti C, Foschi N, Provinciali L, Silvestrini M. Brivaracetam add-on for refractory focal epilepsy: a systematic review and meta-analysis. Neurology. 2016;86(14):1344-1352.

75. Klein P, Biton V, Dilley D, Barnes M, Schiemann J, Lu S. Safety and tolerability of adjunctive brivaracetam as intravenous infusion or bolus in patients with epilepsy. Epilepsia. 2016;57(7):1130-1138.

76. Toledo M, Whitesides J, Schiemann J, et al. Safety, tolerability, and seizure control during long-term treatment with adjunctive brivaracetam for partial-onset seizures. Epilepsia. 2016;57(7):1139-1151.

77. Yates SL, Fakhoury T, Liang W, Eckhardt K, Borghs S, D’Souza J. An open-label, prospective, exploratory study of patients with epilepsy switching from levetiracetam to brivaracetam. Epilepsy Behav. 2015; 52(pt A): $165-168$

78. Brodie MJ, Whitesides J, Schiemann J, D’Souza J, Johnson ME. Tolerability, safety, and efficacy of adjunctive brivaracetam for focal seizures in older patients: a pooled analysis from three phase III studies. Epilepsy Res. 2016;127:114-118.

79. Halász P, Kälviäinen R, Mazurkiewicz-Beldzińska M, et al; SP755 Study Group Adjunctive lacosamide for partial-onset seizures: Efficacy and safety results from a randomized controlled trial. Epilepsia. 2009;50(3):443-453.

80. Chung S, Sperling MR, Biton V, et al; SP754 Study Group. Lacosamide as adjunctive therapy for partial-onset seizures: a randomized controlled trial. Epilepsia. 2010;51(6):958-967.

81. Elger C, Halász P, Maia J, Almeida L, Soares-da-Silva P; BIA-2093301 Investigators Study Group. Efficacy and safety of eslicarbazepine acetate as adjunctive treatment in adults with refractory partial-onset seizures: a randomized, double-blind, placebo-controlled, parallel-group phase III study. Epilepsia. 2009;50(3):454-463.

82. Lagae L, Villanueva V, Meador KJ, et al. Adjunctive perampanel in adolescents with inadequately controlled partial-onset seizures: A randomized study evaluating behavior, efficacy, and safety. Epilepsia. 2016;57(7):1120-1129.

\section{Publish your work in this journal}

Drug Design, Development and Therapy is an international, peerreviewed open-access journal that spans the spectrum of drug design and development through to clinical applications. Clinical outcomes, patient safety, and programs for the development and effective, safe, and sustained use of medicines are the features of the journal, which

\section{Dovepress}

has also been accepted for indexing on PubMed Central. The manuscript management system is completely online and includes a very quick and fair peer-review system, which is all easy to use. Visit http://www.dovepress.com/testimonials.php to read real quotes from published authors. 